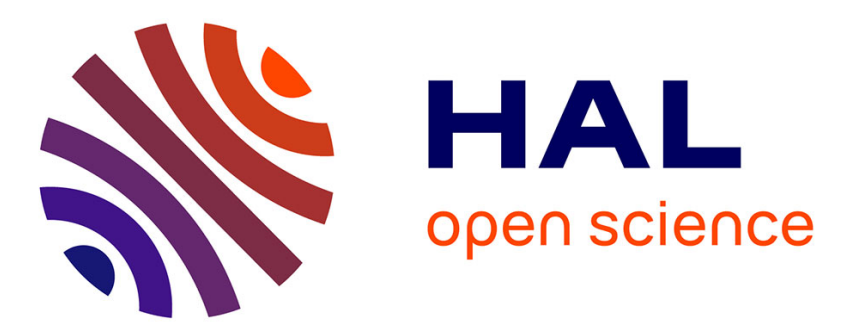

\title{
Comparison of three methods for quantifying topographic complexity on rocky shores
}

Thomas A. Wilding, Edwin J.L. Palmer, Nicholas N.V. Polunin

\section{To cite this version:}

Thomas A. Wilding, Edwin J.L. Palmer, Nicholas N.V. Polunin. Comparison of three methods for quantifying topographic complexity on rocky shores. Marine Environmental Research, 2010, 69 (3), pp.143. 10.1016/j.marenvres.2009.09.005 . hal-00565105

\section{HAL Id: hal-00565105 \\ https://hal.science/hal-00565105}

Submitted on 11 Feb 2011

HAL is a multi-disciplinary open access archive for the deposit and dissemination of scientific research documents, whether they are published or not. The documents may come from teaching and research institutions in France or abroad, or from public or private research centers.
L'archive ouverte pluridisciplinaire HAL, est destinée au dépôt et à la diffusion de documents scientifiques de niveau recherche, publiés ou non, émanant des établissements d'enseignement et de recherche français ou étrangers, des laboratoires publics ou privés. 


\section{Accepted Manuscript}

Comparison of three methods for quantifying topographic complexity on rocky shores

Thomas A. Wilding, Edwin J.L. Palmer, Nicholas N.V. Polunin

PII:

S0141-1136(09)00122-6

DOI:

10.1016/j.marenvres.2009.09.005

Reference:

MERE 3371

To appear in:

Marine Environmental Research

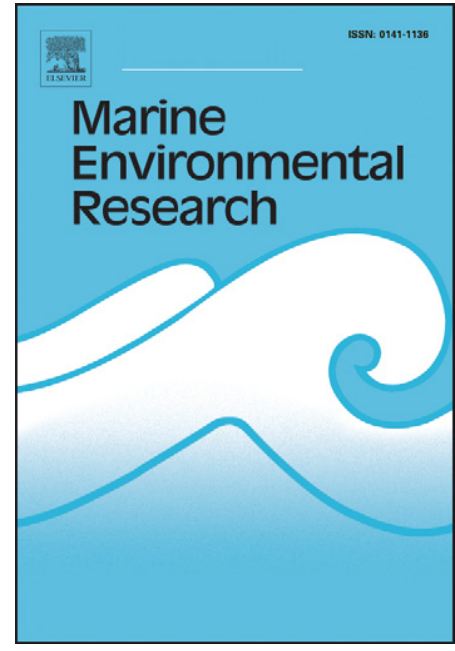

Received Date: $\quad 27$ July 2009

Revised Date: $\quad 16$ September 2009

Accepted Date: $\quad 17$ September 2009

Please cite this article as: Wilding, T.A., Palmer, E.J.L., Polunin, N.N.V., Comparison of three methods for quantifying topographic complexity on rocky shores, Marine Environmental Research (2009), doi: 10.1016/ j.marenvres.2009.09.005

This is a PDF file of an unedited manuscript that has been accepted for publication. As a service to our customers we are providing this early version of the manuscript. The manuscript will undergo copyediting, typesetting, and review of the resulting proof before it is published in its final form. Please note that during the production process errors may be discovered which could affect the content, and all legal disclaimers that apply to the journal pertain. 
Title: Comparison of three methods for quantifying topographic complexity on rocky shores

Thomas A. Wilding, Scottish Association for Marine Science, Dunbeg, OBAN PA37 1QA. UK

Edwin J. L. Palmer, 15 Clifton Road, Newbury, Berks. RG14 5JS

Nicholas N. V. Polunin, School of Marine Science \& Technology, Newcastle University, NE17RU

Corresponding author: Thomas A. Wilding, email tom.wilding@sams.ac.uk. Tel+44(0)1631 559214

Running title: Quantifying topographic complexity on rocky shores 


\section{Abstract}

Topographic complexity (TC) is an important factor in determining community structure in aquatic habitats and there are numerous methods for its estimation. Here we assess and compare three (chain, divider and distance-wheel) methods across different users and substrata over scales of 78 to $1030 \mathrm{~mm}$.

All three techniques showed the same basic trend in TC over different substrata. However, the chain took approximately $1.5 \mathrm{x}$ as long to use, at larger scales $(>271 \mathrm{~mm})$, as the other techniques and resulted in highly variable TC estimates. The chain and divider techniques both have the potential to miss relevantly scaled TC depending on the survey starting point, a disadvantage not suffered by the distance-wheel. TC measured using the distance-wheel was approximately $1.8 \mathrm{x}$ that recorded by the divider technique and significantly $(\mathrm{P}<0.05)$ less variable compared with the chain technique.

The distance-wheel was rapid and easy to use, superior in accessing awkward topographies and has considerable potential for improvement. It is recommended as a technique for estimating the TC of rock-surfaces at scales $>50 \mathrm{~mm}$.

\section{Keywords}

Argyll, Scotland; coastal and rocky shore ecology; community structure; rugosity; habitat space; scale-dependence.

\section{Introduction}

Understanding and predicting the factors that influence species- and size-diversity in benthic communities is a central goal to ecologists. Habitat complexity has been identified as an influential factor in determining occupancy of habitat space: a suitably complex habitat can protect animals and plants from exposure to desiccation (Hooper and Davenport 2006), extremes of wave or tidally induced currents (Guichard and Bourget 1998) and protect against predation (Dayton 1971; Bartholomew et al. 2000; Anderson 2001b; Almany 2004). There is considerable interest in the relationship between scaledependent habitat complexity and community species- and size-structure (reviewed in Robson et al. 
2005) particularly with regard to habitat bottlenecks (Gee and Warwick 1994; Beck 1997; Casariego et al. 2004).

Defining and measuring habitat complexity has proved technically and logistically challenging; Hobson (1972) maintained that a 'single, concise definition of surface roughness is probably impossible' and in an extensive assessment of the literature Bell and McCoy (1991) concluded that there was not one but three aspects (heterogeneity, complexity and scale) of habitat structure that influence the way animals and plants use habitat space. Whilst methods of assessing habitat complexity have included the direct counting and/or measuring of specific features within a given habitat (eg. Kohn 1967; Polunin and Roberts 1993; Charton and Ruzafa 1998; Friedlander and Parrish 1998) such methods are likely to be subjective (Wilson et al. 2007) and numerous, more quantitative methods have been developed. This research focuses on field-based methods of assessing complexity, hereafter referred to as topographic complexity (TC), at scales of $>50 \mathrm{~mm}$.

Methods of assessing scale-dependent TC can be divided into two broad categories: direct and indirect. Indirect techniques adopt a two-step approach to assessing TC, firstly a reproduction (usually in 2 dimensions) of the surface of interest is engineered which is then analysed to generate an index of complexity. Methods of reproducing the surface of interest have included the use of latex to make impressions of individual rocks (Sanson et al. 1995) or the use of plaster of Paris (eg $300 \mathrm{~mm}$ x 300mm Commito and Rusignuolo 2000) to make casts which can then be sectioned to generate a profile. At larger-scales profile gauges are frequently used to reproduce the substratum of interest, normally up to $300 \mathrm{~mm}$ per profile with a $1 \mathrm{~mm}$ resolution using commercially available carpenter's profile gauges (e.g. Sanson et al. 1995; Erlandsson et al. 1999; Beck 2000; Johnson et al. 2003; Devescovi et al. 2005; Frost et al. 2005; Kostylev et al. 2005) although McCormick (1994) demonstrated the use of a much larger (1 m) bespoke profile gauge with a $100 \mathrm{~mm}$ gap between pins (100 mm resolution). Profiles can also be generated using stereo-photographs over relatively small scales (e.g. $0.25 \mathrm{~m} \mathrm{x} 0.25 \mathrm{~m}$, Frost et al. 2005) or larger scales (e.g. 25 x 25 m, Guichard et al. 2000). Various parameters relating to complexity can be determined from profiles including vertical relief, variability in height/angle between points along the profile (for method comparisons see Underwood and Chapman 1989; McCormick 1994; Beck 2000) and the fractal dimension (D) (see extensive reviews in Fielding 1992; Klinkenberg 
1994; Gustafson 1998; Ricotta 2000; Schmid 2000; Halley et al. 2004). Profile gauges and stereophotography are ‘down-from-above’ methods of generating profiles and, consequently, overlook overhangs and horizontally orientated crevices. Such structures are critical components of shores for many species and these techniques are therefore deficient in this regard (Commito and Rusignuolo 2000).

Techniques that can be used in the field to give an immediate measure of TC have the advantage that post-field work laboratory analysis is not required (Frost et al. 2005). In-situ field measurements are usually based on a measurement of step-length-dependent perceived distance compared with the concomitant linear distance between two points over the substratum of interest. Methods for the fielddelineation of the step have including dividers (Bradbury and Reichelt 1983), chains with varying link sizes (Risk 1972; Dahl 1973; Luckhurst and Luckhurst 1978; Archambault and Bourget 1996; Frost et al. 2005; Willis et al. 2005), distance-wheels of differing circumferences (Bourget 1987; Wilding et al. 2007) and rolling-balls of different radii (Robson et al. 2002). In general, when the topographic complexity is at a smaller scale than the step-length then the observing device will effectively ignore (step or roll over) such complexity and the total distance travelled between two points will more closely reflect the linear distance. On the other hand, when traversing a convoluted surface where the steplength is of a scale which enables the measuring device to closely follow the surface topography, the perceived distance will be greater than the linear distance. The ratio between the scale-dependent perceived- and linear-distance, over a surface, is of fundamental interest to this paper. In theory, the perceived distance must show an equal or increasing trend, over the same ground, as the scale of measurement decreases.

Field-based methods of assessing TC need to be easily and rapidly implemented (Hobson 1972) and be cost-effective in order to promote TC evaluation where resources and facilities are limited. They should also be applicable at a broad-range of scales (Halley et al. 2004) and capable of measuring TC which is hidden from above (Commito and Rusignuolo 2000). Whilst the chain, divider and distancewheel techniques meet some of these criteria, little is known as to the comparability of their scaledependent perceived-distance estimates (and why any differences occur) and their respective ease and rapidity of use in the field. 


\section{Materials and methods}

\subsection{Study sites and dates}

The three techniques (chain, divider and distance-wheel) were compared across three shores located in Argyll (Scotland, UK), these were (i) the east shore of Barrnacarry Bay $\left(56.346^{\circ} \mathrm{N}, 5.541^{\circ} \mathrm{W}\right) \mathrm{a}$ millstone grit, (ii) Dunstaffnage Head $\left(56.451^{\circ} \mathrm{N}, 5.450^{\circ} \mathrm{W}\right)$, a conglomerate and (iii) the west shore of Barrnacarry Bay $\left(56.346^{\circ} \mathrm{N}, 5.547^{\circ} \mathrm{W}\right)$, a pre-Cambrian slate (geological details can be found in Stephenson and Gould 1995). The shores were selected to provide varying degrees of TC over which to compare techniques and were not the focus of the study. The surveys were conducted during May 2008.

\subsection{Establishing transects}

The dimensions of areas of the millstone grit and conglomerate shores were approximated by counting paces along the length and width of rectangular (approximately $50 \times 20 \mathrm{~m}$ ) sections of the shore. Transect start points within these rectangular sections were randomly selected by pacing to a random coordinate. The slate shore was broken into 13 rocky outcrops. Two of these were randomly chosen and then the transect-selecting protocol described for the grit and conglomerate shores was followed. The transect line was stretched from the start point along a randomly selected bearing. The line was pulled taught, parallel to the ground, and the rock surface was marked at a linear distance of 10

$\mathrm{m}$. The line was then allowed to drop onto the rock, forming a guideline (augmented with chalk marks) along which the measuring devices were used.

\subsection{Measurement scales}

The three techniques were assessed over five scales that formed an approximate geometric series (as recommended in Klinkenberg 1994) of 1030, 518, 271, 153, and $78 \mathrm{~mm}$. Scale, numbered one to five (largest to smallest) represents the step-length (chains and dividers) and wheel circumference (distancewheel).

Using the number of complete steps to measure perceived distance over a fixed linear distance gives a discrete length category equal to the step-length $\mathrm{x}$ number of steps. In practice most transects do not 
end with a completed step and, at the largest scale (scale 1), a small difference could result in a step completion (or otherwise) at the $10 \mathrm{~m}$ mark potentially creating a discrepancy of up to $10 \%$ (where there are approximately 10 steps per transect). To overcome this source of error, the number of complete steps up to, and beyond where necessary, the $10 \mathrm{~m}$ mark was noted (Klinkenberg and Goodchild 1992; Klinkenberg 1994). The distance beyond the $10 \mathrm{~m}$ mark required to complete the last step ('completion distance') was recorded. The perceived/linear distance-ratio was then calculated as:

Number of steps x step-length (mm) / 10,000 mm + completion distance (mm).

\subsection{Techniques}

Commercial chains with link lengths equivalent to the large step lengths of interest in this study would be unwieldy, therefore the design was based on a functionally similar, but much lighter and more practical surveyor's or Gunter's chain (Toscano 1991) where links are connected via eyes at their ends. Chains at the three smallest scales (Scales 3, 4 and 5) were made using 3.5mm PVC coated wire. Surveyor chain links of the two larger scales (1 and 2) were made using $4 \mathrm{~mm}$, galvanized mild steel wire. The centrally aligned, tear-shaped eyes of each link were made large enough to allow free movement between the links but minimal slippage between links. The chain was deployed sequentially, from the eye of the previous link, and held in place on any contact points while the next link was positioned.

The three largest divider sizes (scales 1, 2 and 3) were based on simple 'A'-shaped frames, constructed using plastic rods (8mm diameter) sharpened at their ends. A pair of navigation dividers (Ultralight Dividers/Compass, Weems and Plath) were used to delineate the two smaller scales. The dividers were 'walked' down the transect line and the number of steps recorded.

The distance-wheel system described in Wilding et al (2007) was used with the following modifications: the wheels were edged with a ribbed foam rubber strip (10 x $3 \mathrm{~mm})$ to improve traction and the electronic counter was removed. Wheels were rolled along the transect and the number of rotations counted.

\subsection{Experimental design and data analysis}


The data were collected by two users, on three different shores (two transects per shore), using three different techniques over five scales. At each level of user, shore, transect, technique and scale five repeated measurements of the same transect were taken. Transects were surveyed in the same direction each time and the total time taken to complete the five measurements was recorded to the nearest minute. The total sample size was 900 . Repeated surveying of the same transect was necessary to evaluate technique consistency over the same ground. These repeated measures are not replicate transects and were pooled to generate the mean perceived: linear distance ratio (see below).

Three response variables were analysed: 1$)$ the mean $(n=5)$ perceived: linear distance-ratio of the five repeated measures of the same transect ( $n=900 / 5=180$; see above), 2) the range, per five repeated measurements over the same transect ( $n=180$; see above) and 3) the time taken to conduct five repeated measurements combined across two users ( $\mathrm{n}=90)$.

Scale and technique were considered fixed factors. Shores were identified from a number of options that offered varying degrees of complexity on the basis of ease of access. As assessing differences in complexity between specific shore-types was not the goal of this study shore was considered a random factor. Transect, nested in shore, and user were both random factors. The main factor of interest was technique and its interaction with other factors, particularly scale, and how this interaction changed over different shores (or transects within shore). Other factors (even where significant) are not discussed.

These data were analysed using PERMANOVA (Primer-E Ltd, Plymouth, UK). PERMANOVA is frequently used in the analysis of multivariate data but can, as here, be used to perform univariate analyses in order to overcome the distributional and homoscedasticity restrictions of ANOVA. PERMANOVA is based on distance matrices (Anderson 2001a; Anderson et al. 2008) and generates a permutation-based pseudo-F (P-F) statistic. In order to use PERMANOVA, the response variables (mean distance ratio, range and time) were, individually, converted to a Euclidean distance matrix and the full model (all main effects and interactions) was then fitted and tested with 9999 permutations. There was no replication at the highest level (technique $\mathrm{x}$ scale $\mathrm{x}$ user $\mathrm{x}$ transect(shore)) and, initially, this term formed the residual. Non-significant $(\mathrm{P}>0.25$, Underwood 1997) interaction terms were sequentially pooled, beginning with term with the smallest (least significant) mean-square (Anderson et al. 2008) whilst maintaining factor hierarchy (i.e retaining non-significant factors/interactions if 
subordinate interactions were significant). Any negative variance components that remained after this process were kept in the model (and assumed to represent an underestimate of a zero-variance component; Underwood 1997). The number of unique permutations associated with each factor during analysis using PERMANOVA was noted and, where this was low, Monte-Carlo methods were used to assess significance (Anderson et al. 2008).

Reduced major axis regression was used to investigate the functional relationship between perceived distance (explanatory factor) and range following log transformation of both to linearise the relationship (least squares regression was not appropriate as measurement error applied to both variables; Sokal and Rohlf 1995). Major axis regression (used where both variables are measured on the same scale; Sokal and Rohlf 1995) was used to establish if the relationship between ratios generated using different pairs of techniques differed (regression coefficient 99\% confidence intervals that did not include a slope of 1 were considered different).

A posteriori pairwise comparisons of fixed effects and their interactions, were conducted using PERMANOVA and reported where significant. The relative importance of both fixed and random effects were evaluated by comparison of components of variation (Anderson et al. 2008) expressed as a percentage of total variation. Other analyses were done using Minitab ${ }^{\mathrm{TM}}$ v15.

\section{Results}

\subsection{Technique efficacy}

The use of all three techniques was physically demanding over long periods (6 hours). At largescales the chain technique was unwieldy and awkward to use, otherwise techniques were roughly equivalent in their ease of use.

Survey times ranged from a minimum (per transect) of 1 minute (four occurrences, on the conglomerate and millstone shores using divider and wheel techniques at scales of 1 and 2) to a maximum of 9.6 minutes, using the chain technique on the slate shores (transect 1 ) at scale 5. Overall, the time required to traverse each transect was overwhelmingly influenced by scale ( $\mathrm{P}-\mathrm{F}=46.8,4 \mathrm{df}$, 
$\mathrm{P}=0.001,63 \%$ of total variation; Table 1 ), with the large scales being quicker to use than the smaller scales (Figure 1).

The scale effect on survey time was modified by technique such that at the smallest scale (Scale 5) all techniques took approximately the same time to use (mean 5.7 minutes per transect) whilst at the largest scale the chain technique took approximately $1.5 \mathrm{x}$ as long to use (mean per transect 2.33 minutes compared with both the divider and distance-wheel technique means of 1.53 and 1.52 minutes respectively, Figure 1; scale $\mathrm{x}$ technique $\mathrm{P}-\mathrm{F}=2.91,8 \mathrm{df}, \mathrm{P}=0.004,1.6 \%$ variance). The time taken to use the divider and wheel techniques was approximately the same for all scales (Figure 1).

\subsection{Comparison of ratios between technique, scales and users}

The mean distance-ratio $(n=5)$ varied from a minimum of 1.003 (conglomerate shore, transect 2, divider technique, scale=2) to 1.655 (slate shore, transect 1 , wheel technique, scale=5) with the scale of measurement making a significant difference to the distance-ratio $(\mathrm{P}-\mathrm{F}=9.24, \mathrm{df}=4, \mathrm{P}=0.001$ contributing $20 \%$ of variation; Table 2). Whilst all three distance measuring techniques indicated similar trends of increased distance-ratio, and variability in distance-ratio, as step-size decreased the measured distance-ratio differed between techniques ( $\mathrm{P}-\mathrm{F}=7.71, \mathrm{df}=2, \mathrm{P}=0.019$ contributing $13 \%$ of variation; Table 2) and was highest when measured using the distance wheel, then chain, followed by the divider technique (mean ratios of 1.21, 1.17 and 1.09 respectively). The effect of technique varied between locations (transect(shore) $x$ technique, $P-F=28.1, d f=6, P=0.001$, contributing $3.2 \%$ of variance).

The relationship between distance ratios generated by the different techniques was relatively consistent with correlations between all techniques exceeding $0.9(\mathrm{P}<0.001, \mathrm{n}=60$; Table 3$)$. There was no evidence that the chain and distance-wheel techniques generated ratios that were significantly different (major axis regression coefficient and 95\% CI was $1.082(0.9975,1.175)$. However, distanceratio generated by the chain and distance-wheels differed from that generated using the divider technique, for example, the regression coefficient and 99\% confidence interval was $1.820(1.558,2.155)$ when comparing the distance wheel and divider techniques (Table 3). Over the same ground, the distance wheel and chain techniques measured approximately 1.8 and 1.7 (respectively) times the distance measured using the dividers (Table 3). 
The total proportion of variance in distance-ratio accounted for by the main effects (scale, location (consisting of shore and transect(shore)) and technique) was $84 \%$ indicating that interactions were of relatively minor importance. However, the scale effect was influenced by the transect within shore being surveyed (transect (shore) $\mathrm{x}$ scale, $\mathrm{P}-\mathrm{F}=26.5, \mathrm{df}=12, \mathrm{P}=0.001$, contributing $5.0 \%$ of variance; Table 2); the scale effect was greater on the slate shore (transect 1) compared with the other shores (the degree of association was greater for slate (transect 1) compared to the other transects; Figure 2). Occasionally, whilst using the chain technique only, the measured perceived distance was greater at larger step-lengths, a theoretical impossibility (see 4.2).

The user-effect appeared the least when using the distance wheel as demonstrated by the almost complete parity (overlap) between measurements taken by different users, on all shores, at all scales as when compared to either the chain or dividers techniques (user $\mathrm{x}$ shore $\mathrm{x}$ technique $\mathrm{P}-\mathrm{F}=3.20,4 \mathrm{df}$, $\mathrm{P}=0.014,0.26 \%$ of total variation; Figure 3 ).

\subsection{Repeatability}

Precision was assessed by measuring the range generated between repeated measurements taken over the same transect with lower ranges indicating greater precision. There were significant differences in range between techniques ( $\mathrm{P}-\mathrm{F}=10.6, \mathrm{P}=0.037,2 \mathrm{df}, 21 \%$ of variance; Table 4). The range associated with the distance-wheel was the lowest $(0.0503 \mathrm{~m})$ followed by the divider technique $(0.0858 \mathrm{~m})$, both of which were significantly (PERMANOVA pair-wise comparisons, $\mathrm{P}=0.032$ and $\mathrm{P}=0.030$ respectively) lower than the range generated using the chain technique (range $=0.140 \mathrm{~m}$ ) which was the least precise.

Range generally increased with scale number (i.e with decreasing step-length) (P-F=29.6, 4df, $\mathrm{P}=0.023,10.2 \%$ total variation; Figure 4) but this effect was moderated by the transect dependent effect of technique (transect (shore) $\mathrm{x}$ technique x scale; $\mathrm{P}-\mathrm{F}=1.83, \mathrm{P}=0.032$, 24df, $15 \%$ of total variation; Table 4) with the trend of increasing range with scale associated with the chain technique being less apparent (Figure 4).

At perceived distance-ratios of more than approximately 1.05, the distance-wheel was more precise than the divider technique such that at a distance-ratio of 1.25 the mean range associated with the distance-wheel was approximately half that associated with the divider technique (Figure 5). The range 
in perceived-distance was consistently greater when using the chain compared with the distance wheel, over all measured mean distance ratios (as indicated by the near-parallel regression lines in Figure 5). However, the relationship between log range and log mean ratio demonstrated by the chain and distance-wheel were both approximately half that measured using the divider technique (reduced major axis regression coefficient (with 99\% confidence interval) for the chain technique was $6.28(4.50,8.06)$ for the wheel technique it was $7.48(5.52,9.44)$ neither of which overlapped the divider's regression coefficient 99\% CI (regression coefficient and 99\% CI of 14.87 (11.51, 18.24)).

\section{Discussion}

The chain, divider and wheel techniques all demonstrated an increase in the mean distance-ratio as a function of decreasing scale and all showed broadly similar trends over transects of differing complexity. All three sets of equipment were cheap and easy to manufacture and similar in terms of ease of transport (across shores etc). No special training was required to use any of the equipment and, as with all direct techniques, there was no further effort required to obtain topographic complexity (TC) estimates (i.e. no laboratory analysis). In this way all three techniques had an advantage over indirect techniques, which necessitate time-consuming laboratory analysis (eg. of photographs; Frost et al (2005). None of the approaches used here (chains, dividers or the distance-wheel) are 'down-fromabove' techniques (compare with profile gauges and stereophotography) and all have the potential advantage of assessing complexity that is not accessible from above (Commito and Rusignuolo 2000). However, there were significant differences among TC estimates made using the chain, divider and distance-wheel techniques.

\subsection{Comparison of methods as used in the field}

The different methods differed in their ease of use with the distance-wheel and dividers being approximately equivalent in terms of ease of use and time taken to deploy. Extended use of these techniques, particularly at the smaller scales and over more angular substrata was physically demanding. The use of Gunter's chains in measuring complexity offers considerable advantages over normal (free-linked) chains as there cannot be slippage, recognized as a problem (Frost et al. 2005), 
between the links. In addition, the link size is at the user's discretion unlike commercial chains. The Gunter’s chains were light and allowed easy extension of the upper step-length limit. However, maintaining contact between the links and the substratum, necessary to correctly deploy subsequent links, was difficult particularly when using the larger links over angular topographies. Consequently, the time taken to use the chains, at larger scales (scales $1-3,270-1030 \mathrm{~mm}$ ), was approximately $1.5 \mathrm{x}$ as long as the same measurements taken using the other two techniques. Using the distance-wheel or divider techniques the measurement of transects in excess of $100 \mathrm{~m}$ would have been practicable at the larger scales (1 and 2). The scales used here are in excess of much of those in the published literature making efficacy comparisons with other approaches difficult. However, McCormick(1994), using a profile gauge with $100 \mathrm{~mm}$ pin separations (i.e. steps) took approximately five minutes to survey a $3 \mathrm{~m}$ transect. At the most comparable scale reported here (Scale 5, $78 \mathrm{~mm}$ ) a $10 \mathrm{~m}$ transect took approximately 5.5 minutes so, all the techniques reported here are about 3 times as rapid to deploy as profile gauges at relatively small scales.

Ease of access to recesses (caves, overhangs etc) differed between techniques. The chain could be lowered into vertical crevices, unlike the dividers, but neither the chain nor the dividers could conveniently access horizontal crevices smaller than the user's hand (whilst holding and manipulating the equipment). This disadvantage did not extend to the distance-wheel which, because of the handle, was able to conveniently access such smaller recesses. The divider and chain technique are able to access recesses that are smaller, in terms of their opening, than the step distance (depending on the location of the previous step; Figure 6) which contrasts with the distance-wheel which is limited to accessing openings of greater than step-length/Pi (i.e. the wheels diameter; compare Figure 6a, $d$ and e). Where there are many crevices with small aspect ratios (i.e. deep and narrow) then the wheel technique will measure an increase in perceived distance at a smaller scale compared to the other methods (but it will capture that complexity and with potentially less variability, see below). Conversely, some ecologically relevant recesses which are insufficiently deep to be 'observed' by the chain or divider techniques will still influence the distance-wheel's distance-ratio. Further research is required to determine exactly how different techniques measure perceived distance and how this is affected by both 
the shape and the scale of the TC. The relevance of any differences may depend on the nature (shape) of the fauna occupying and exploiting the habitat space.

\subsection{Comparison of perceived-distances and repeatability}

The differences in perceived-distance and repeatability recorded between the techniques were partly dependent on the shore being assessed and it seems reasonable to assume that these differences were, at least partly, step-number dependent with technique-differences potentially manifesting themselves at each step. As a consequence, it seems likely that more complex shores and/or measuring at smaller scales, both of which result in more steps, will exacerbate differences between techniques. This would account for the complex interactions observed, for example, that differences between the interaction between technique and scale differed between transects. Notwithstanding these interactions, in terms of perceived-distances and repeatability, three basic conclusions can be drawn regarding the three techniques (i) the divider method resulted in consistently lower perceived distance-ratios compared with the other methods, (ii) the chain method showed consistently greater variability compared with both other techniques and (iii) the wheel method showed reduced variability compared with the chain method, delivered the highest perceived distance measures and its precision was least affected by perceived distance.

Frost et al (2005) concluded that consistency in the relative complexity ranking obtained using stereo-photography, chains and profile gauges on the same type of shore cannot be assumed. Our research concurs with this general finding, that there are significant differences in perceived-distance as assessed using different techniques. Here, the distance-wheel and chain techniques result in perceived distances that are approximately $1.75 \mathrm{x}$ that recorded by the divider technique. This obviously invalidates uncorrected comparisons between sites measured using the described techniques. However, the correlations between perceived distances measured using the different techniques (chain v. divider v. distance-wheel) were all $>0.9$ and much greater that those found by Frost et al (2005) (comparing stereo-photography, profile gauges and chains, $r$ maximum 0.404 ) even over the greater range of shores reported here. Corrections enabling the direct comparison between estimates of shore perceiveddistance, made using these different techniques might be acceptable (depending on the study objectives). 
There are several reasons that could explain the deficiencies in, and differences between, distance ratios estimated using the chain, divider and distance-wheel techniques. The use of Gunter's chains effectively prevents link slippage (Frost et al. 2005) and this cannot be responsible for the lack of repeatability observed when using the chain technique reported here. In the current case, the high variability in the use of the chains stemmed from two factors. The first factor, which it shares with the divider technique, involves the way the chain link is able to bridge gaps and, consequently, not measure topographic complexity that might be of a relevant scale (Figure $6 a v b$ and Figure $6 c v d$ ). The effect of this process is to cause an overall reduction in the distance-ratio measured using the chain or divider techniques, compared with the wheel technique (Figure 6e), and increase the data's variability over the same transect. An additional error applicable to the chain technique was caused by small, angular topographic features such that location of the end of the preceding link had a profound influence on the chain's perceived distance (Figure 7a); each topographic irregularity potentially adding two steps to the overall perceived-distance. This amplification of the perceived distance was frequently observed whilst using the chain technique and has the effect of increasing the overall perceived distance, increasing the variability in the data and occasionally inversing the relationship between step length and perceived distance (i.e. measuring a shorter perceived distance using a smaller step-length which is contrary to theory; Schmid 2000). These effects were particularly noticeable (and significant) whilst using the largest links but apply to any chain link, whether a Gunter's chain (as here) or a standard chain, of any length. On the varied shores measured in the current case, this amplification effect more than outweighed the reduction in perceived distance occurring as a consequence of stepping over complexity.

The amplification of perceived distance, as illustrated in Figure 7a, was not an issue for either the divider technique (because there is no link between the divider points) or the distance-wheel approach. However, the dividers were occasionally impractical in use where they were unable to adequately make a step as a consequence, again, of angular topography ('faltered-step') and were left hanging above the substratum (Figure 7b). The amplification and faltered-step effects are both dependent on the transect start point and will occur more frequently where more steps are taken (i.e. on more complex shores) as 
indicated by significant interactions between the main effects and transect(shore)). Whilst their effects can be addressed by starting the transect at different points (as recommended in Sugihara and May 1990; Klinkenberg 1994) the sample mean will always underestimate perceived distance unless countered by unpredictable and varying degrees of 'distance-amplification' (chain technique only). The distance-wheel, which is basically a field-based approximation of the surface-monolayer method of assessing perceived distance (Fielding 1992) or the rolling disc method (as applied to digitised images at the mm scale by Sanson et al. 1995) is not influenced in this way as its path is the same, along the same transect, regardless of the starting point.

\section{Conclusions}

Different methods of measuring topographic complexity are not consistent, either in the distanceratios they produce or their variability over the same ground. At the larger scales (1030 and $518 \mathrm{~mm}$ ) the chain technique was slow to use and resulted in occasional, but considerable, amplification of the perceived-distance. This amplification resulted in high variability in perceived distance over the same ground. For these reasons we do not recommend the chain technique at the scales used here.

The divider technique resulted in the lowest perceived distances and was prone to higher variability (as a proportion of perceived distance) and user-error when compared to the wheel technique. Unlike the other techniques, the distance wheel offers considerable scope for improvement, for example, by fitting an electronic counter and improving the bearing both of which would decrease survey time and increase repeatability. The distance-wheel, as described here, is recommended for the direct estimation of rocky shore TC at scales of approximately 50 - $1000 \mathrm{~mm}$ and, with simple modification, should be applicable to a broader range of scales.

\section{Acknowledgments}

This work was supported by the Natural Environmental Research Council under Oceans 2025, Theme 4.6. 


\section{References}

Almany G.R., 2004. Does increased habitat complexity reduce predation and competition in coral reef fish assemblages? Oikos 106 (2), 275-284

Anderson M.J., 2001a. A new method for non-parametric multivariate analysis of variance. Austral Ecology 26 (1), 32-46

Anderson M.J., Gorley R.N., Clarke K.R. 2008. PERMANOVA+ for PRIMER: Guide to software and statistical methods. Primer-E: Plymouth, UK.

Anderson T.W., 2001b. Predator responses, prey refuges, and density-dependent mortality of a marine fish. Ecology 82 (1), 245-257

Archambault P., Bourget E., 1996. Scales of coastal heterogeneity and benthic intertidal species richness, diversity and abundance. Marine Ecology-Progress Series 136 (1-3), 111-121

Bartholomew A., Diaz R.J., Cicchetti G., 2000. New dimensionless indices of structural habitat complexity: predicted and actual effects on a predator's foraging success. Marine EcologyProgress Series 206, 45-58

Beck M.W., 1997. A test of the generality of the effects of shelter bottlenecks in four stone crab populations. Ecology 78 (8), 2487-2503

Beck M.W., 2000. Separating the elements of habitat structure: independent effects of habitat complexity and structural components on rocky intertidal gastropods. Journal of Experimental Marine Biology and Ecology 249 (1), 29-49

Bell S.S., McCoy E.D. 1991. Habitat structure: the evolution and diversification of a complex topic. In: Bell SS, McCoy ED, Mushinsky HR (eds) Habitat structure - the physical arrangement of objects in space. Chapman and Hall, London, pp 3 -17

Bourget E. 1987. Barnacle larval settlement: the perception of cues at different spatial scales. In: Chelazzi L, Vanni MJ (eds) Behavioural adaption to intertidal life. Plenum Press, New York, London, pp 153 - 172

Bradbury R.H., Reichelt R.E., 1983. Fractal Dimension of a Coral-Reef at Ecological Scales. Marine Ecology-Progress Series 10 (2), 169-171

Casariego A.M., Schwindt E., Iribarne O., 2004. Evidence of habitat structure-generated bottleneck in the recruitment process of the SW Atlantic crab Cyrtograpsus angulatus. Marine Biology 145 (2), 259-264

Charton J.A.G., Ruzafa A.P., 1998. Correlation between habitat structure and a rocky reef fish assemblage in the southwest Mediterranean. Marine Ecology-Pubblicazioni Della Stazione Zoologica Di Napoli I 19 (2), 111-128

Commito J.A., Rusignuolo B.R., 2000. Structural complexity in mussel beds: the fractal geometry of surface topography. Journal of Experimental Marine Biology and Ecology 255 (2), 133-152

Dahl A.L., 1973. Surface-Area in Ecological Analysis - Quantification of Benthic Coral-Reef Algae. Marine Biology 23 (4), 239-249

Dayton P.K., 1971. Competition, disturbance, and community organization - provision and subsequent utilization of space in a rocky intertidal community. Ecological Monographs 41 (4), 351-389

Devescovi M., Ozretic B., Ivesa L., 2005. Impact of date mussel harvesting on the rocky bottom structural complexity along the Istrian coast (Northern Adriatic, Croatia). Journal of Experimental Marine Biology and Ecology 325 (2), 134-145

Erlandsson J., Kostylev V., Williams G.A., 1999. A field technique for estimating the influence of surface complexity on movement tortuosity in the tropical limpet Cellana grata Gould. Ophelia 50 (3), 215-224

Fielding A., 1992. Applications of Fractal Geometry to Biology. Computer Applications in the Biosciences 8 (4), 359-366

Friedlander A.M., Parrish J.D., 1998. Habitat characteristics affecting fish assemblages on a Hawaiian coral reef. Journal Of Experimental Marine Biology and Ecology 224 (1), 1-30

Frost N.J., Burrows M.T., Johnson M.P., Hanley M.E., Hawkins S.J., 2005. Measuring surface complexity in ecological studies. Limnology and Oceanography: Methods 3, 203 - 210 
Gee J.M., Warwick R.M., 1994. Body-Size Distribution in a Marine Metazoan Community and the Fractal Dimensions of Macroalgae. Journal of Experimental Marine Biology and Ecology 178 (2), 247-259

Guichard F., Bourget E., 1998. Topographic heterogeneity, hydrodynamics, and benthic community structure: a scale-dependent cascade. Marine Ecology-Progress Series 171, 59-70

Guichard F., Bourget E., Agnard J.P., 2000. High-resolution remote sensing of intertidal ecosystems: A low-cost technique to link scale-dependent patterns and processes. Limnology and Oceanography 45 (2), 328-338

Gustafson E.J., 1998. Quantifying landscape spatial pattern: What is the state of the art? Ecosystems 1 (2), 143-156

Halley J.M., Hartley S., Kallimanis A.S., Kunin W.E., Lennon J.J., Sgardelis S.P., 2004. Uses and abuses of fractal methodology in ecology. Ecology Letters 7 (3), 254-271

Hobson R.D. 1972. Surface roughness in topography: a quantitative approach. In: Chorley RJ (ed) Spatial analysis in geomorphology. Metheun and Co. Ltd, London, pp 221 - 245

Hooper G.J., Davenport J., 2006. Epifaunal composition and fractal dimensions of intertidal marine macroalgae in relation to emersion. Journal of the Marine Biological Association of the United Kingdom 86 (6), 1297-1304

Johnson M.P., Frost N.J., Mosley M.W.J., Roberts M.F., Hawkins S.J., 2003. The area-independent effects of habitat complexity on biodiversity vary between regions. Ecology Letters 6 (2), 126132

Klinkenberg B., 1994. A Review of Methods Used to Determine the Fractal Dimension of Linear Features. Mathematical Geology 26 (1), 23-46

Klinkenberg B., Goodchild M.F., 1992. The fractal properties of topography - a comparison of methods. Earth Surface Processes and Landforms 17 (3), 217-234

Kohn A., 1967. Environmental complexity and species diversity in gastropod genus Conus on Indowest Pacific reef platforms. American Naturalist 101, 251 -260

Kostylev V.E., Erlandsson J., Ming M.Y., Williams G.A., 2005. The relative importance of habitat complexity and surface area in assessing biodiversity: Fractal application on rocky shores. Ecological Complexity 2 (3), 272-286

Luckhurst B.E., Luckhurst K., 1978. Analysis of Influence of Substrate Variables on Coral-Reef Fish Communities. Marine Biology 49 (4), 317-323

McCormick M.I., 1994. Comparison of Field Methods for Measuring Surface-Topography and Their Associations with a Tropical Reef Fish Assemblage. Marine Ecology-Progress Series 112 (1-2), 87-96

Polunin N.V.C., Roberts C.M., 1993. Greater Biomass and Value of Target Coral-Reef Fishes in 2 Small Caribbean Marine Reserves. Marine Ecology-Progress Series 100 (1-2), 167-176

Ricotta C., 2000. From theoretical ecology to statistical physics and back: self- similar landscape metrics as a synthesis of ecological diversity and geometrical complexity. Ecological Modelling $125(2-3), 245-253$

Risk M.J., 1972. Fish diversity on a coral reef in the Virgin Islands. Atoll Research Bulletin 153, 1 - 6

Robson B.J., Barmuta L.A., Fairweather P.G., 2005. Methodological and conceptual issues in the search for a relationship between animal body-size distributions and benthic habitat architecture. Marine and Freshwater Research 56 (1), 1-11

Robson B.J., Chester E.T., Barmuta L.A., 2002. Using fractal geometry to make rapid field measurements of riverbed topography at ecologically useful spatial scales. Marine and Freshwater Research 53 (6), 999-1003

Sanson G.D., Stolk R., Downes B.J., 1995. A new method for characterizing surface-roughness and available space in biological systems. Functional Ecology 9 (1), 127-135

Schmid P.E., 2000. Fractal properties of habitat and patch structure in benthic ecosystems. Advances in Ecological Research 30, 339-401

Sokal R.R., Rohlf F.J. 1995. Biometry: the principles and practice of statistics in biological research. W. H. Freeman and Company, New York

Stephenson D., Gould D., 1995. The Grampian Highlands. British Regional Geology, HMSO. Fourth Edition. ISBN 011884521 7. 261 pages

Sugihara G., May R., M, 1990. Applications of fractals in ecology. Trends in Ecology \& Evolution 5 (3), 79-86 
Toscano P., 1991. The Gunter's chain. Surveying and Land Information Systems 51, 155 - 161

Underwood A.J. 1997. Experiments in ecology: their logical design and interpretation using analysis of variance. Cambridge University Press, Cambridge, UK

Underwood A.J., Chapman M.G., 1989. Experimental analyses of the influences of topograpahy of the substratum on movements and density of an intertidal snail Littorina unifasciata. Journal of Experimental Marine Biology and Ecology 134 (3), 175-196

Wilding T.A., Rose C.A., Downie M.J., 2007. A novel approach to measuring subtidal habitat complexity. Journal of Experimental Marine Biology and Ecology 353 (2), 279-286

Willis S.C., Winemiller K.O., Lopez-Fernandez H., 2005. Habitat structural complexity and morphological diversity of fish assemblages in a Neotropical floodplain river. Oecologia 142 (2), 284-295

Wilson S.K., Graham N.A.J., Polunin N.V.C., 2007. Appraisal of visual assessments of habitat complexity and benthic composition on coral reefs. Marine Biology 151 (3), 1069-1076 

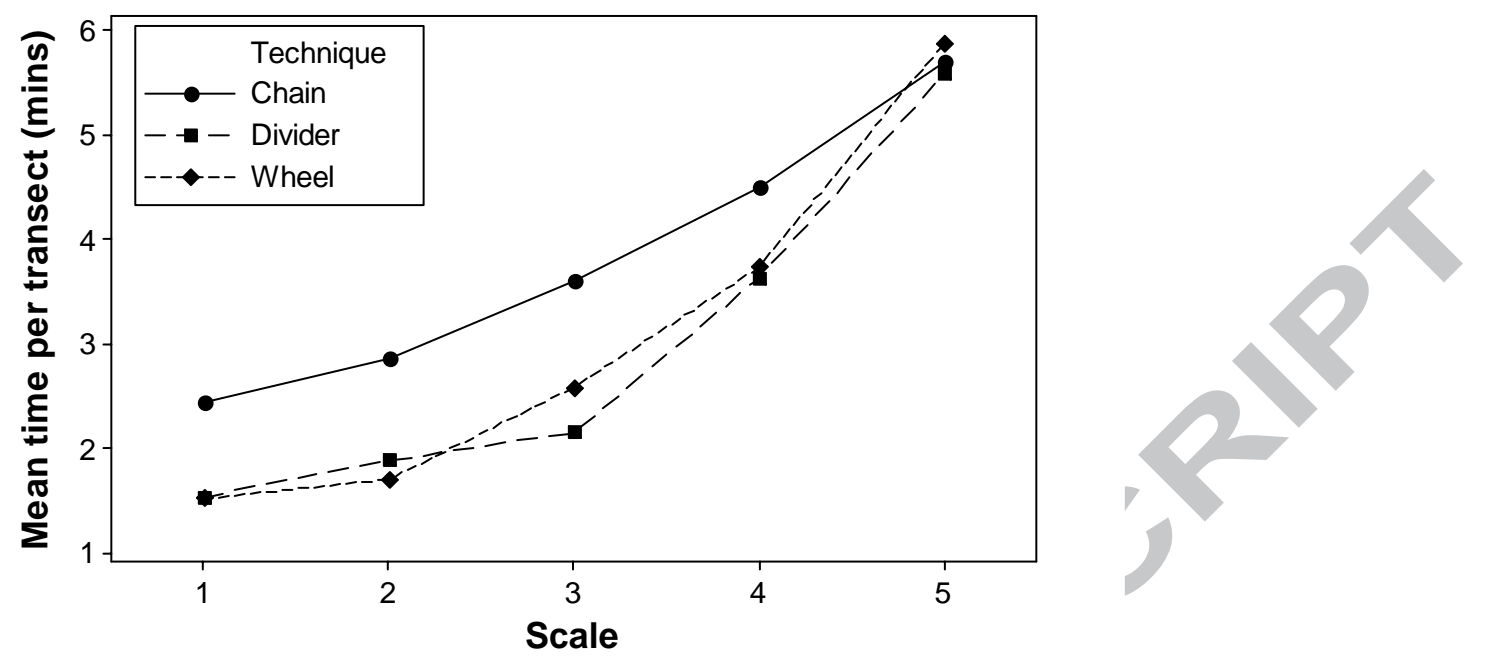

Figure 1 - Mean ( $\mathrm{n}=12)$ time per transect (mins) v. scale number for chain, divider and distance-wheel techniques (scale numbers (in mm): 1 - 1030, 2 - 518, 3 - 271, 4 - 153, 5 - 78). 


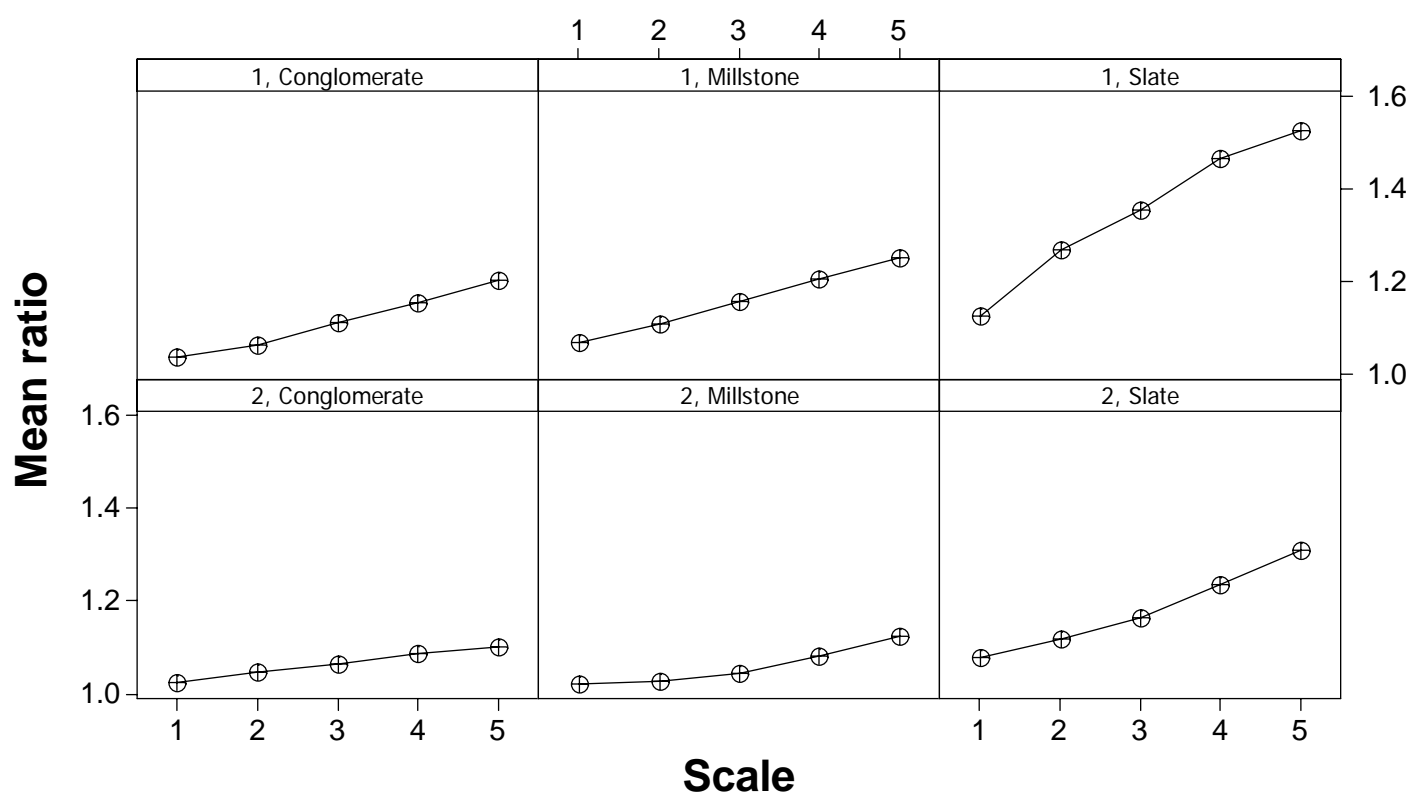

Figure 2 - The relationship between mean $(\mathrm{n}=6)$ perceived-distance ratio and scale at different transects (1 or 2) on different shores (conglomerate, millstone or slate). The scale effect (gradient of the association) varies widely between different transects on the same shore. Scale numbers (in mm): 1 1030, $2-518,3-271,4-153,5-78$. 


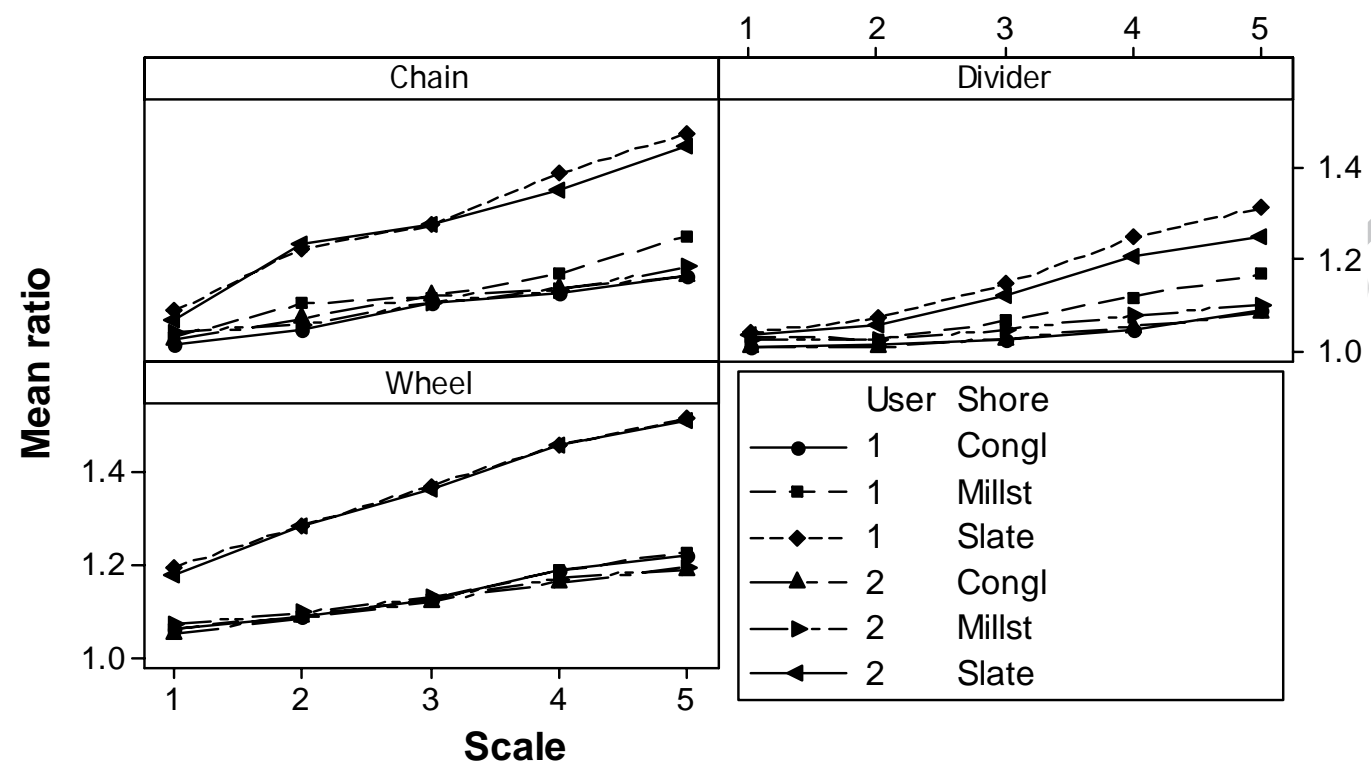

Figure 3 - Differences in distance-ratio measured by different users (1 or 2) as a function of technique and scale over the different shores (congl=conglomerate, millst=millstone). The near complete overlap of the measurements made using the distance-wheel indicate a negligible user-effect compared with the divider or chain technique. Scale numbers (in mm): 1 - 1030, 2 - 518, 3 - 271, 4 - 153, 5 - 78. 


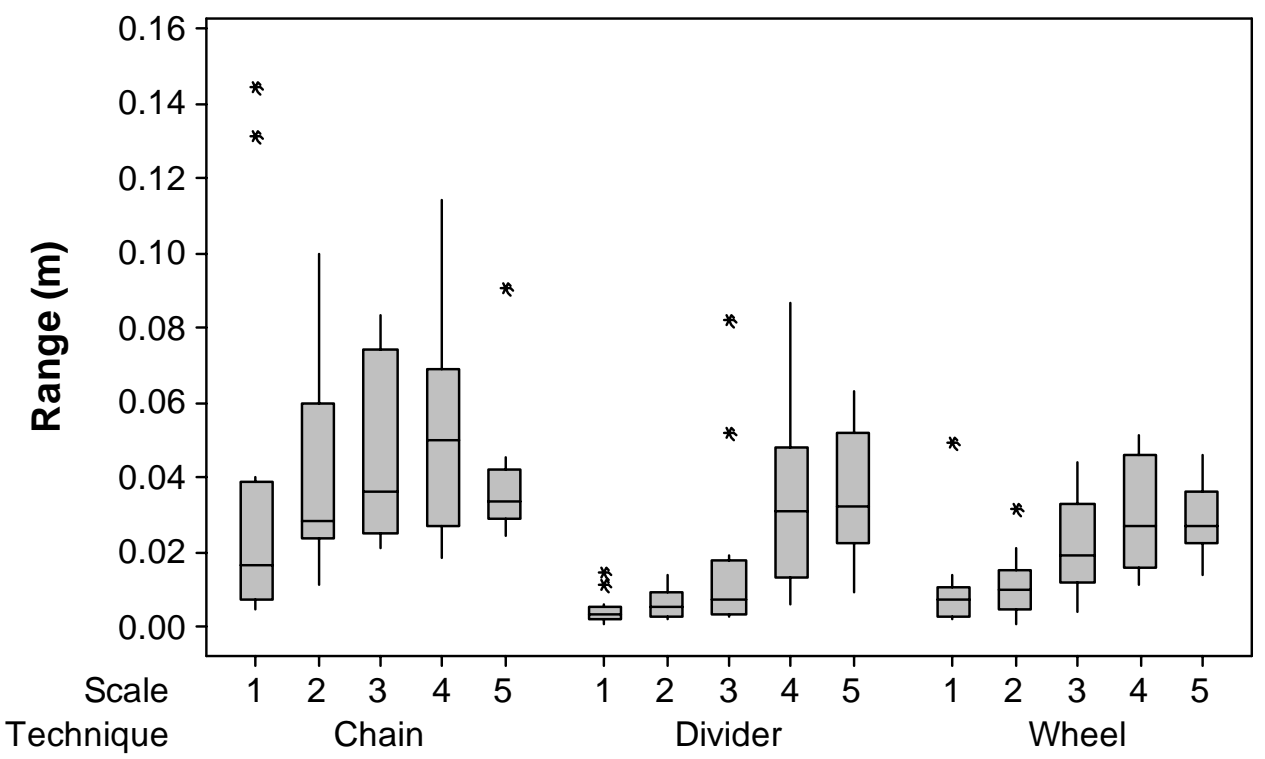

Figure 4 - Range (m) in distance-ratio (over five measurements) per technique and scale combination $(\mathrm{n}=12)$ per transect $(10 \mathrm{~m})$. The box show the interquartile range bisected by a line representing the median, outliers are indicated by asterixes. Scale numbers (in mm): 1 - 1030, 2 - 518, 3 - 271, 4 - 153, $5-78$. 


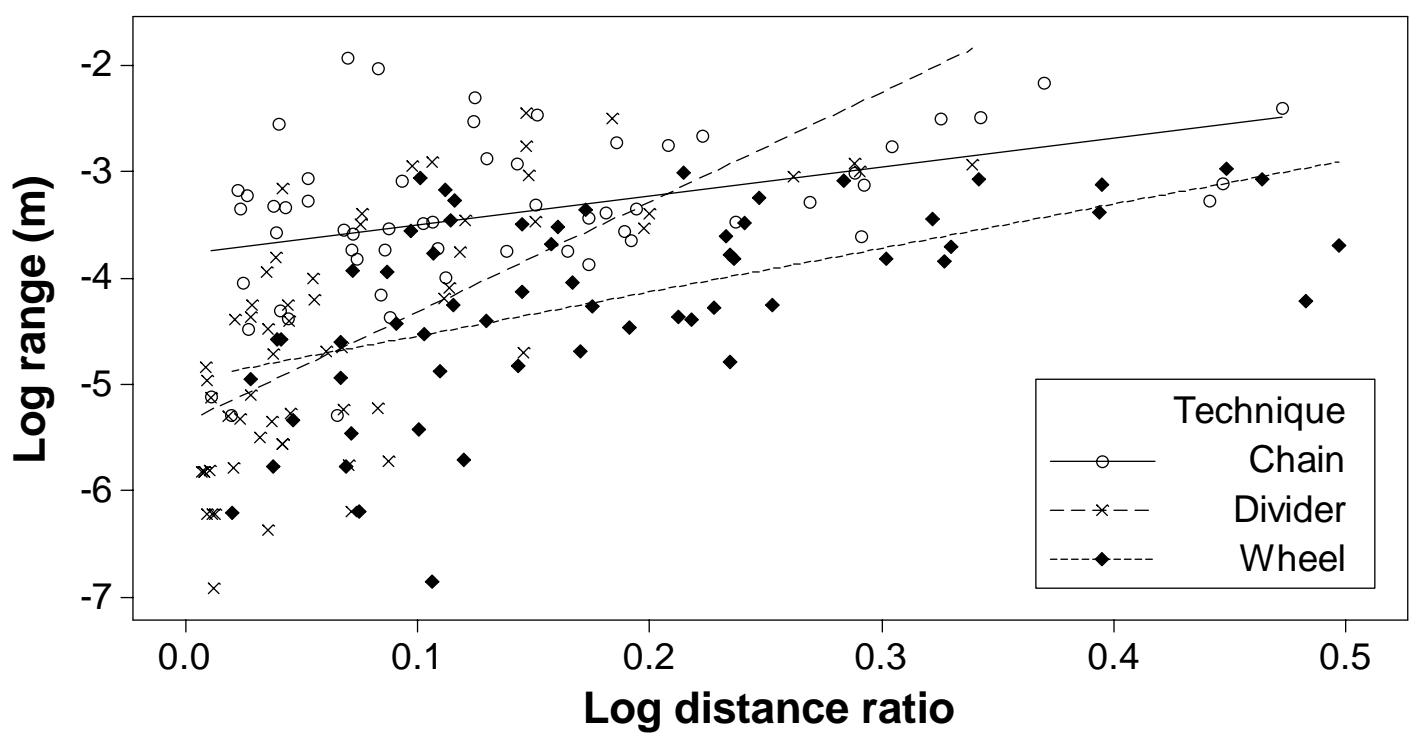

Figure 5 - Log range as a function of log mean distance ratio for the chain, divider and distance-wheel techniques. Increasingly complex shores (increasing log mean distance ratios) are associated with increasing range (i.e. decreasing repeatability) for all techniques but this relationship is greatest for the divider technique and is most variable when using the chain technique. 
(a)

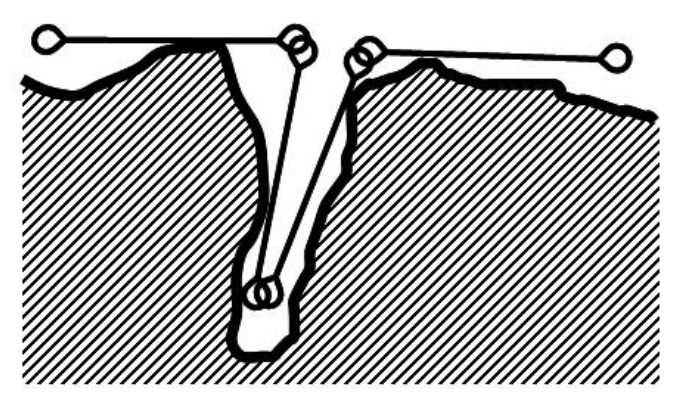

(c)
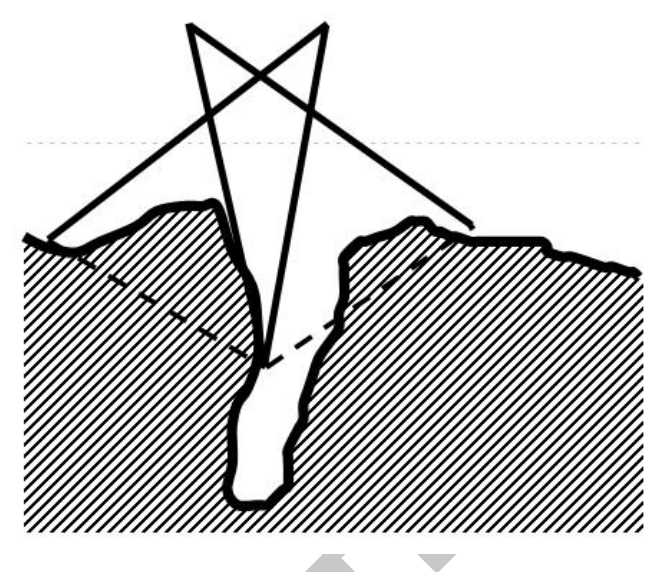

(e)

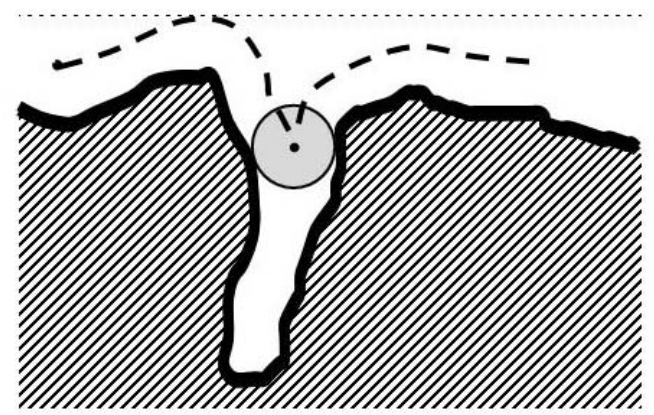

(b)

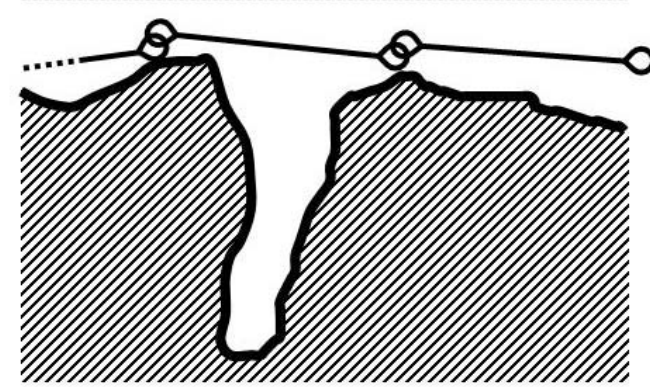

(d)

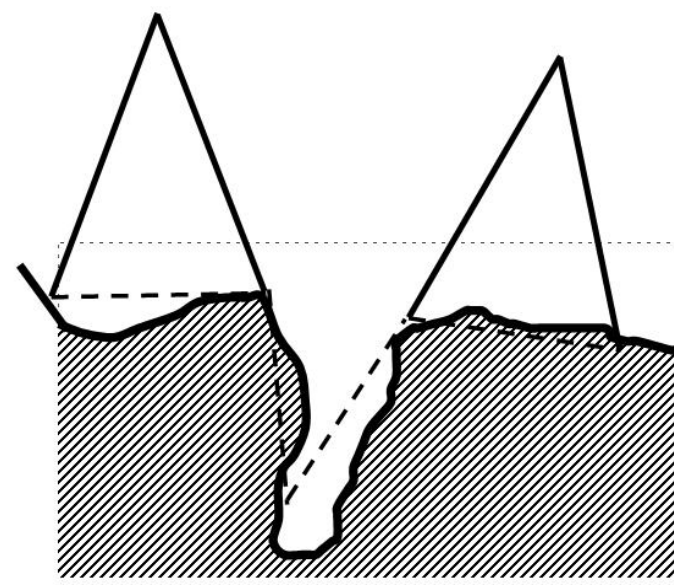

Figure 6 Variations in the assessment of topographic complexity using different techniques where steplength is identical. Where shown the dotted lines indicate the perceived distance. In (d) the middletwo dividers are not shown for clarity, their steps are indicated by the dotted line 
a)

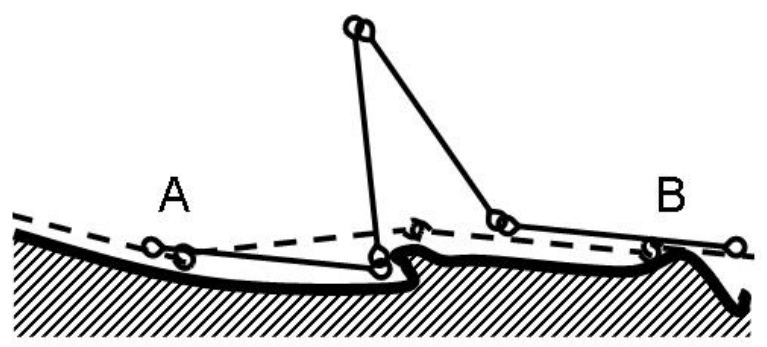

b)

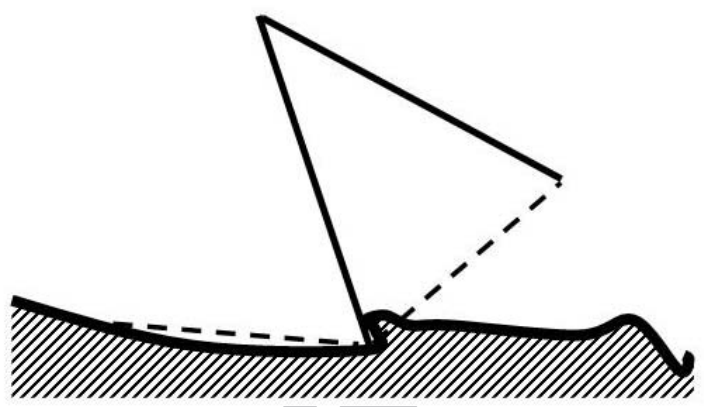

Figure 7 Perceived distance measured over identical profiles by (a) chain method illustrating how the perceived distance $\mathrm{AB}$ varies between approximately 2 steps and $>3.5$ steps depending on the previous link or start position (b) dividers method showing a 'faltered step' (the divider's previous step is indicated by the dotted line) 
Table 1 - Results of the PERMANOVA test on survey time. Sources of variation: Sh=shore, Te=technique, $\mathrm{Sc}=$ scale, $\operatorname{Tr}(\mathrm{Sh})=$ transect nested in shore. $\mathrm{df}=$ degrees of freedom, $\mathrm{MS}=$ mean squares, $\mathrm{P}-\mathrm{F}=$ pseudo-F statistic, $\mathrm{P}($ perm)=permutational probability (significant effects are highlighted in bold), $\%$ variance $=\%$ variation (of total) of each variance source. The number of unique permutations generated by PERMANOVA, for each factor, was >6000 except for Shore where it was 15 (the MonteCarlo significance result is shown in parenthesis).

$\begin{array}{lccccc}\text { Source } & \text { df } & \text { MS } & \text { P-F } & \text { P(perm) } & \text { \% variance } \\ \text { Sh } & 2 & 28.5 & 3.58 & 0.135(0.164) & 8.6 \\ \text { Te } & 2 & 11.8 & 7.00 & \mathbf{0 . 0 4 9} & 4.2 \\ \text { Sc } & 4 & 92.3 & 46.8 & \mathbf{0 . 0 0 1} & 63 \\ \text { Tr(Sh) } & 3 & 7.98 & 20.4 & \mathbf{0 . 0 0 1} & 6.3 \\ \text { Sh x Te } & 4 & 1.69 & 0.957 & 0.491 & 0.00 \\ \text { Sh x Sc } & 8 & 1.97 & 5.04 & \mathbf{0 . 0 0 1} & 3.3 \\ \text { Te x Sc } & 8 & 1.14 & 2.91 & \mathbf{0 . 0 0 4} & 1.6 \\ \text { Tr(Sh) x Te } & 6 & 1.77 & 4.51 & \mathbf{0 . 0 0 1} & 3.4 \\ \text { Total } & 179 & & & & \end{array}$


Table 2 - Results of the PERMANOVA test on perceived-distance ratio. Sources of variation: Us=user, $\mathrm{Sh}=$ shore, $\mathrm{Te}=$ technique, $\mathrm{Sc}=$ scale, $\operatorname{Tr}(\mathrm{Sh})=$ transect nested in shore. $\mathrm{df}=$ degrees of freedom, SS =sum of squares, MS= mean squares, $\mathrm{P}-\mathrm{F}=$ pseudo-F statistic, $\mathrm{P}($ perm $)=$ =ermutational probability (significant effects are highlighted in bold), \% variance $=\%$ variation (of total) of each variance source. The number of unique permutations generated by PERMANOVA, for each factor, was $>9000$ except for User where it was 38 (the Monte-Carlo significance result is shown in parenthesis).

\begin{tabular}{|c|c|c|c|c|c|}
\hline Source & df & MS & P-F & $\mathrm{P}($ perm $)$ & \% variance \\
\hline Us & 1 & $7.07 \mathrm{E}-3$ & 4.41 & $0.239(0.174)$ & 0.23 \\
\hline Sh & 2 & 0.556 & 2.81 & 0.107 & 22 \\
\hline $\mathrm{Te}$ & 2 & 0.242 & 7.71 & 0.019 & 13 \\
\hline Sc & 4 & 0.213 & 9.24 & 0.001 & 20 \\
\hline $\operatorname{Tr}(\mathrm{Sh})$ & 3 & 0.196 & 283 & 0.003 & 24 \\
\hline Us $x$ Sh & 2 & $1.60 \mathrm{E}-3$ & 2.31 & 0.285 & 0.11 \\
\hline Us x Te & 2 & 4.47E-4 & 0.444 & 0.684 & -0.07 \\
\hline Us $\mathrm{x}$ Sc & & & 5.06 & 0.002 & 0.27 \\
\hline Sh $x$ Te & & $3.10 \mathrm{E}-2$ & 3.17 & 0.012 & 4.0 \\
\hline Sh $x$ Sc & 8 & $2.15 \mathrm{E}-2$ & 2.57 & 0.063 & 4.1 \\
\hline Te x Sc & 8 & $4.34 \mathrm{E}-3$ & 7.60 & 0.001 & 1.2 \\
\hline Us x $\operatorname{Tr}(\mathrm{Sh})$ & 3 & $6.94 \mathrm{E}-4$ & 2.20 & 0.095 & 0.09 \\
\hline $\operatorname{Tr}(\mathrm{Sh}) \times \mathrm{Te}$ & 6 & 8.88E-3 & 28.1 & 0.001 & 3.2 \\
\hline $\operatorname{Tr}(\mathrm{Sh}) \mathrm{x}$ Sc & 12 & 8.37E-3 & 26.5 & 0.001 & 5.0 \\
\hline Us $x$ Sh $x \mathrm{Te}$ & 4 & $1.01 \mathrm{E}-3$ & 3.20 & 0.014 & 0.26 \\
\hline Sh $x$ Te $x$ Sc & 16 & $5.71 \mathrm{E}-4$ & 0.485 & 0.933 & -0.56 \\
\hline $\operatorname{Tr}(\mathrm{Sh}) \times \mathrm{Te} \times \mathrm{Sc}$ & 24 & $1.18 \mathrm{E}-3$ & 3.73 & 0.001 & 1.61 \\
\hline Total & 179 & & & & \\
\hline
\end{tabular}


Table 3 - Comparison (major axis regression) of distance-ratios produced using the three techniques $(n=60), C I=$ confidence interval of regression coefficients. All correlations were highly significant $(\mathrm{P}<0.001)$.

Regression equation

Chain $=-0.635+1.660$ Divider

Wheel $=-0.052+1.082$ Chain

Wheel $=-0.764+1.820$ Divider
CI (95\%)

$1.499,1.848$

0.9975, 1.175

1.618, 2.063
CI (99\%)

1.450, 1.917

0.9709, 1.208

1.558, 2.155
Correlation

0.929

0.955

0.908 
Table 4 - Results of the PERMANOVA test on range. Sources of variation: $\mathrm{Sh}=$ shore, $\mathrm{Te}=$ technique, $\mathrm{Sc}=$ scale, $\operatorname{Tr}(\mathrm{Sh})=$ transect nested in shore. $\mathrm{df}=$ degrees of freedom, $\mathrm{MS}=$ mean squares, $\mathrm{P}-\mathrm{F}=$ pseudo- $\mathrm{F}$ statistic, $\mathrm{P}($ perm)=permutational probability (significant effects are highlighted in bold), $\%$ variation = $\%$ variation (of total) of each variance source. The number of unique permutations generated by PERMANOVA, for each factor, was >6000 except for Shore where it was 15 (the Monte-Carlo significance result is shown in parenthesis).

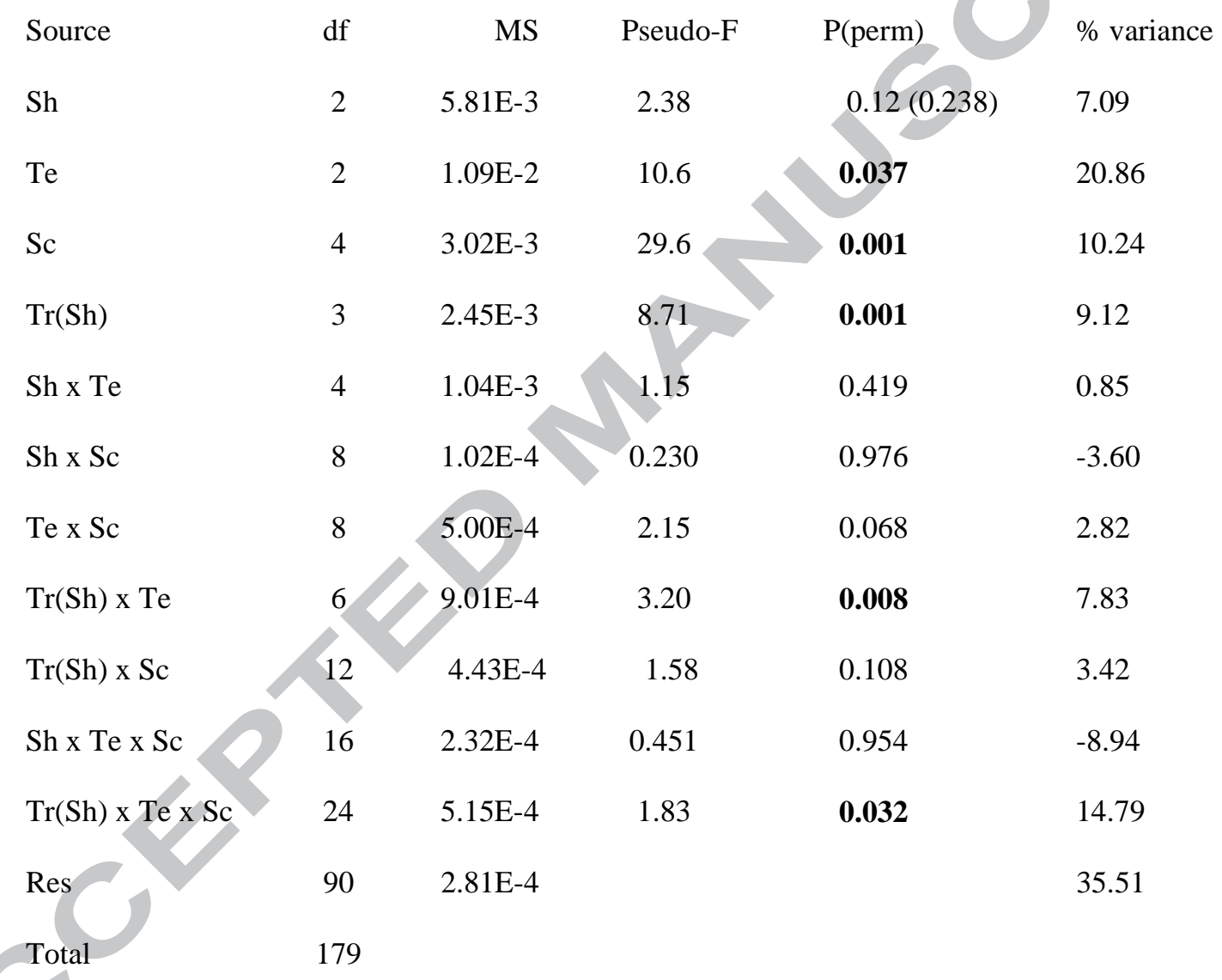

